\title{
Incorporation of fluoride ions into calcite - Effect of organic materials and magnesium ions in a parent solution
}

\author{
Minoru OKumura ${ }^{1}$, Yasushi Kitano ${ }^{2}$ and Masatoshi Idogaki ${ }^{1}$ \\ Faculty of Science, Shimane University, Matsue ${ }^{1}$ and \\ Water Research Institute, Nagoya University, Nagoya ${ }^{2}$, Japan
}

(Received November 2, 1982: Accepted July 11, 1983)

\begin{abstract}
The effect of citrate, malate, lactate and acetate ions in a parent solution on the incorporation of fluoride ions into formed calcite has been studied experimentally.

Citrate ions in a parent solution containing no magnesium ions increase intensively the amount of fluoride ions incorporated into magnesium-free calcite, and malate ions do so but moderately, while lactate and acetate ions have little effect on the incorporation of fluoride ions into calcite.

The amount of fluoride ions incorporated into low Mg-calcite (smaller than 4\% magnesium carbonate) formed from a parent solution containing magnesium ions but no citrate ions remarkably increases with increasing magnesium carbonate content of the formed low Mg-calcite. This trend is in agreement with that observed in marine calcareous skeletons (OHDE and KITANO, 1980). The amount of fluoride ions incorporated into high $\mathrm{Mg}$-calcite formed from a parent solution containing both magnesium and citrate ions is large. The fluoride amount slightly increases with increasing magnesium carbonate content of the formed high Mg-calcite.
\end{abstract}

\section{INTRODUCTION}

Carbonate sediments usually contain a significant amount of fluoride and play an important role in the geochemical balance of fluoride ions (CARPENTER, 1969, OKUMURA et al., 1983).

The fluorine content of calcium carbonate has been studied actively through laboratory experiments and field observations (KITANO and OKumura, 1973; AKaiwa and Aizawa, 1979; ICHIKUNI, 1979; KitANO et al., 1980; OHDE and Kitano, 1980). The laboratory experiments showed that the coprecipitation of fluoride ions with calcium carbonate is controlled by (a) the crystal form of calcium carbonate formed and (b) the presence of certain cations such as magnesium, copper (II) and zinc ions in a parent solution and also in carbonate precipitate (KITANo and OKUMURA, 1973; KitANo et al., 1980; OHDE and KitANO, 1980). These controlling factors have also been confirmed by observations on the uptake of fluoride ions by marine calcareous skeletons (CARPENTER, 1969; OHDE and Kitano, 1980; OKumura et al., 1983).

It was reported that the coprecipitation of divalent cations is strongly affected by organic materials such as citrate ions in a parent solution, because of their complex formation capacity (KitANo et al., 1968, 1971). However, the relation of organic materials in body fluids of marine calcareous organisms with fluoride incorporation into calcium carbonate has not been studied.

The purpose of this paper is to examine experimentally the effects of organic anions on fluoride incorporation into calcareous skeletons. The organic anions used in the present experiment are citrate, malate, lactate and acetate ions, which are observed in body fluids of marine calcareous organisms.

\section{EXPERIMENTAL}

Reagents and solution - Calcium bicarbonate 
solution: Calcium carbonate suspended solution was bubbled with carbon dioxide gas for four hours and filtered. The filtrate was bubbled again with carbon dioxide gas for half an hour. Reagent grade sodium fluoride, magnesium chloride, sodium citrate, sodium malate and sodium acetate were used.

Lactate solution: A solution of $\mathrm{pH} 7.0$ was prepared from the acid form of reagent lactic acid by addition of sodium hydroxide solution and distilled water.

Experimental procedure - Various amounts of organic material and magnesium chloride were placed in calcium bicarbonate solution $\left(\mathrm{Ca}^{2+}: 360 \mathrm{mg} / \mathrm{l}\right)$ containing sodium flouride $\left(\mathrm{F}^{-}: 1.0\right.$ or $\left.2.0 \mathrm{mg} / 1\right)$. The parent solutions were vigorously stirred with magnetic stirrer (stirring system) or allowed to stand with occasional agitation (non-stirring system) at $25^{\circ} \mathrm{C}$, until about $50 \%$ of calcium ions were precipitated as calcium carbonate. The experiment on the effect of magnesium ions on the fluoride incorporation was carried out in both stirring and non-stirring systems, because stirring of a parent solution has a significant influence on magnesium carbonate content of formed calcite (Kitano and Kanamori, 1966; Kitano et al., 1976). And the other experiments were done only in the non-stirring system. The calcium carbonate precipitate was filtered off, washed with distilled water, and then air-dried at room temperature. One portion of the dried precipitate was used for the determination of fluorine and magnesium contents and another portion for the indentification of the crystal form.

Calcium ions in a solution were determined volumetrically with the EDTA standard solution. Fluorine content of calcium carbonate was determined colorimerically with combined lanthanumalizarine complexon reagent (GREENHALGH and RILEY, 1961) after the removal of interfering cations by using cation exchange resine, and magnesium content with an atomic absorption spectrometer. The crystal form was identified with an X-ray diffractometer.

\section{RESUlTS AND Discussion}

The presence of magnesium ions in a parent solution favors aragonite formation, and that of certain organic materials favors calcite formation (KITANo and Hood, 1965). Magnesian calcite is formed from calcium bicarbonate solution containing both magnesium ions and certain organic materials (KITANO and KANAMORI, 1966). Low Mg-calcite, high Mgcalcite (magnesian calcite), or aragonite is formed, depending on the concentrations of certain organic material and magnesium ions in the parent solution.

Magnesium carbonate in resulting calcites was confirmed to be contained as a form of a solid solution, $(\mathrm{Ca}, \mathrm{Mg}) \mathrm{CO}_{3} \quad$ (KITANO and KANAMORI, 1966).

Effect of organic anions - The incorporation experiment was carried out in the following solution system; $\mathrm{Ca}\left(\mathrm{HCO}_{3}\right)_{2}+\mathrm{NaF}\left(\mathrm{F}^{-}: 1.0\right.$ $\mathrm{mg} / \mathrm{l})+$ organic material (citrate, malate, lactate or acetate: 0 to $1.58 \mathrm{mmol} / \mathrm{l}) \longrightarrow$ Magnesiumfree calcite.

The parent solutions in this experimental system were allowed to stand during calcite precipitation (non-stirring system). Only calcite was precipitated from the parent solutions containing these organic materials.

Figure 1 shows the amount of fluoride ions incorporated into calcite as a function of concentration of organic material in the parent solution. The presence of citrate or malate ions in the parent solution enhances the incorporation of fluoride ions into magnesium-free calcite formed. That is, the fluorine content of the magnesium-free calcite remarkably increases with increasing concentration of citrate ions in the parent solution until 0.5 $\mathrm{mmol} / \mathrm{l}$, and then remains almost constant along with the further increase in citrate concentration. With increasing concentration of malate ions, the fluorine content moderately increases. However, lactate and acetate ions in the parent solution only slightly affect the fluoride incorporation. The extent of the effect of these organic materials on the fluoride 
incorporation increases in the following order; citrate $>$ malate $>$ lactate $\geq$ acetate. This order is in good agreement with that of the extent of their complex formation with calcium ions and also that of their influence on magnesian calcite formation (KitaNo and HoOD, 1965; KitANO and KANAMORI, 1966).

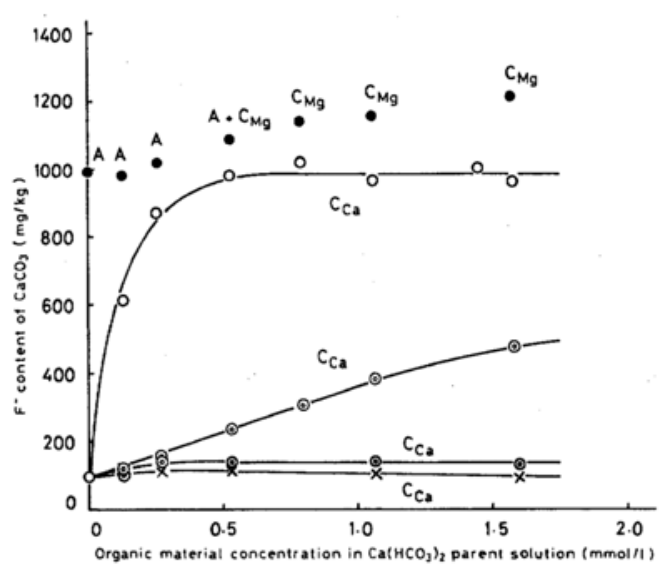

Fig. 1. Influence of organic material in a parent solution on the incorporation of fluoride ions into calcium carbonate.

Non-stirring system

- citrate $\mathrm{Ca}\left(\mathrm{HCO}_{3}\right)_{2}\left(\mathrm{Ca}^{2+}: 360 \mathrm{mg} / \mathrm{l}\right)+\mathrm{NaF}$

( ) malate $\left\{\left(F^{-}: 1.0 \mathrm{mg} / \mathrm{l}\right)+\right.$ organic material (citrate,

- lactate malate, lactate or acetate: 0 to 1.58

$\times$ acetate $\mathrm{mmol} / \mathrm{l}) \longrightarrow$ Magnesium-free calcite

- $\mathrm{Ca}\left(\mathrm{HCO}_{3}\right)_{2}\left(\mathrm{Ca}^{2+} ; 360 \mathrm{mg} / \mathrm{l}\right)+\mathrm{NaF}\left(\mathrm{F}^{-}: 1.0 \mathrm{mg} / \mathrm{l}\right)+$ Na-citrate (citrate: 0 to $1.58 \mathrm{mmol} / \mathrm{l})+\mathrm{MgCl}_{2}\left(\mathrm{Mg}^{2+}\right.$ : $1.27 \mathrm{~g} / \mathrm{l}) \longrightarrow$ Magnesian calcite and or Aragonite $C_{C a}, A, C_{M g}$ and $A+C_{M g}$ denote magnesium-free calcite, aragonite, magnesian calcite and the mixture of magnesian calcite and aragonite, respectively.

It was found through microscopical observation and X-ray diffraction that the presence of organic material in a parent solution shows significant effects on the crystalinity and the shape of formed calcite: (a) Reflected X-ray intensity of calcite formed from the parent solution containing organic material, especially citrate ions, is lower than that of calcite from the solution without organic material. This indicates that the presence of citrate ions in the parent solution decreases the crystalinity of formed calcite. (b) Rod-like crystals of calcite were formed from the parent solution containing citrate or malate ions, although typical rhombohedral crystals of calcite is formed from the solution containing no organic material or from the solution containing lactate or acetate ions.

It was reported already that the presence of only a small amount of citrate and malate ions in a parent solution greatly decreases the rate of calcite formation and favors the formation of magnesian calcite, and the presence of lactate and acetate ions slightly decreases the former and favors the latter (KITANo and Hood, 1965; KitANO et al., 1976).

These experimental results suggest that citrate and malate ions in a parent solution affect significantly the nucleation and the crystal growth of calcite to change the crystalinity and the shape, probably owing to the incorporation of those organic anions into the formed calcite through the association of those organic anions with calcium (CARTER, 1978; CARTER and MitTerer, 1978; LAHANN and CAMPBEll, 1980).

Such a change of the crystalinity and the shape of formed magnesium-free calcite by citrate and malate ions may serve to enhance the fluoride incorporation into the calcite.

Effect of magnesium ions - To clarify the effect of magnesium ions on the fluoride incorporation into calcite, the incorporation experiment was carried out in the following solution system; $\mathrm{Ca}\left(\mathrm{HCO}_{3}\right)_{2}+\mathrm{NaF}\left(\mathrm{F}^{-}: 1.0\right.$ or $2.0 \mathrm{mg} / \mathrm{l})+\mathrm{MgCl}_{2}\left(\mathrm{Mg}^{2+}: 0\right.$ to $\left.0.3 \mathrm{~g} / \mathrm{l}\right)$ $\longrightarrow$ Low Mg-calcite; or Low Mg-calcite + Aragonite.

The parent solutions in this experimental system were stirred (stirring system) or kept to stand (non-stirring system). It was known that magnesium ions in a parent solution favor aragonite formation (KITANO et al., 1972) and fluoride ions favor calcite formation (KITANO and OKumura, 1973; Kitano et al., 1980). The mixture of calcite and aragonite was precipitated from the parent solutions containing both $1.0 \mathrm{mg} / 1$ of fluoride ions and 0.15 to $0.3 \mathrm{~g} / 1$ of magnesium ions and also from those containing both $2.0 \mathrm{mg} / 1$ of fluoride ions and 0.2 
to $0.3 \mathrm{~g} / 1$ of magnesium ions. Only calcite was precipitated from the parent solutions containing both $1.0 \mathrm{mg} / \mathrm{l}$ of fluoride ions and 0 to $0.1 \mathrm{~g} / 1$ of magnesium ions and also from those containing both $2.0 \mathrm{mg} / 1$ of fluoride ions and 0 to $0.15 \mathrm{~g} / 1$ of magnesium ions. Most of the calcites formed in this experimental system were low Mg-calcite. Figure 2 shows the influence of magnesium ions on the fluoride incorporation into calcites from the parent solutions containing $1.0 \mathrm{mg} / 1$ of fluoride ions. A similar influence was also observed in the parent solutions containing $2.0 \mathrm{mg} / 1$ of fluoride ions.

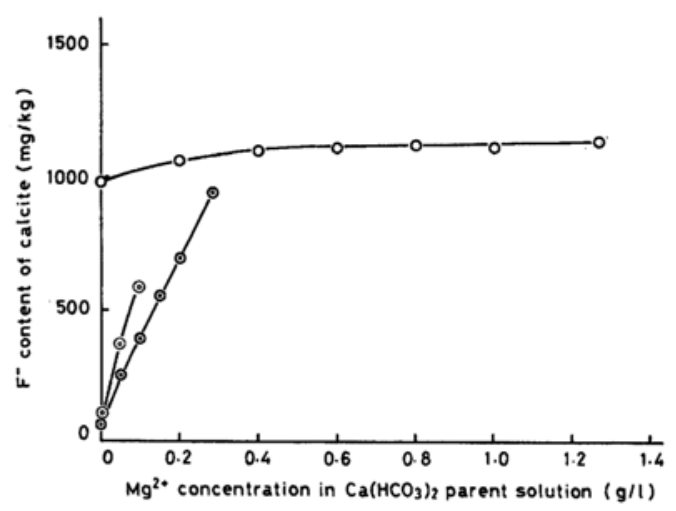

Fig. 2. Influence of magnesium ions in a parent solution on the incorporation of fluoride ions into calcite.

Stirring system

- $\mathrm{Ca}\left(\mathrm{HCO}_{3}\right)_{2}\left(\mathrm{Ca}^{2+}: 360 \mathrm{mg} / \mathrm{l}\right)+\mathrm{NaF}\left(\mathrm{F}^{-}: 1.0 \mathrm{mg} / \mathrm{l}\right)$ $+\mathrm{MgCl}_{2}\left(\mathrm{Mg}^{2+}: 0\right.$ to $\left.0.3 \mathrm{~g} / \mathrm{l}\right) \longrightarrow$ Calcite

Non-stirring system

- $\mathrm{Ca}\left(\mathrm{HCO}_{3}\right)_{2}\left(\mathrm{Ca}^{2+}: 360 \mathrm{mg} / \mathrm{l}\right)+\mathrm{NaF}\left(\mathrm{F}^{-}: 1.0 \mathrm{mg} / \mathrm{l}\right)$ $+\mathrm{MgCl}_{2}\left(\mathrm{Mg}^{2+}: 0\right.$ to $\left.0.1 \mathrm{~g} / \mathrm{l}\right) \longrightarrow$ Calcite or Calcite + Aragonite

- $\mathrm{Ca}\left(\mathrm{HCO}_{3}\right)_{2}\left(\mathrm{Ca}^{2+}: 360 \mathrm{mg} / \mathrm{l}\right)+\mathrm{NaF}\left(\mathrm{F}^{-}: 1.0 \mathrm{mg} / \mathrm{l}\right)+$ $\mathrm{MgCl}_{2}\left(\mathrm{Mg}^{2+}: 0\right.$ to $\left.1.27 \mathrm{~g} / \mathrm{l}\right)+\mathrm{Na}$-citrate (citrate: $1.06 \mathrm{mmol} / \mathrm{l}) \longrightarrow$ Calcite

Figure 3 shows the relationship between fluorine and magnesium carbonate contents of low $\mathrm{Mg}$ calcite. As seen from these figures, the amount of fluoride ions incorporated into low $\mathrm{Mg}$-calcite markedly increases with increasing concentration of magnesium ions in the parent solution and also with increasing magnesium carbonate content of low Mg-calcite. The increase in the fluorine content of low Mg-calcite with in- creasing concentration of magnesium ions in the parent solution is higher in non-stirring system than in stirring system (see Fig. 2). But the rate of increase in the fluorine content with increasing magnesium carbonate content of low $\mathrm{Mg}$ calcite is similar in both systems (see Fig. 3).

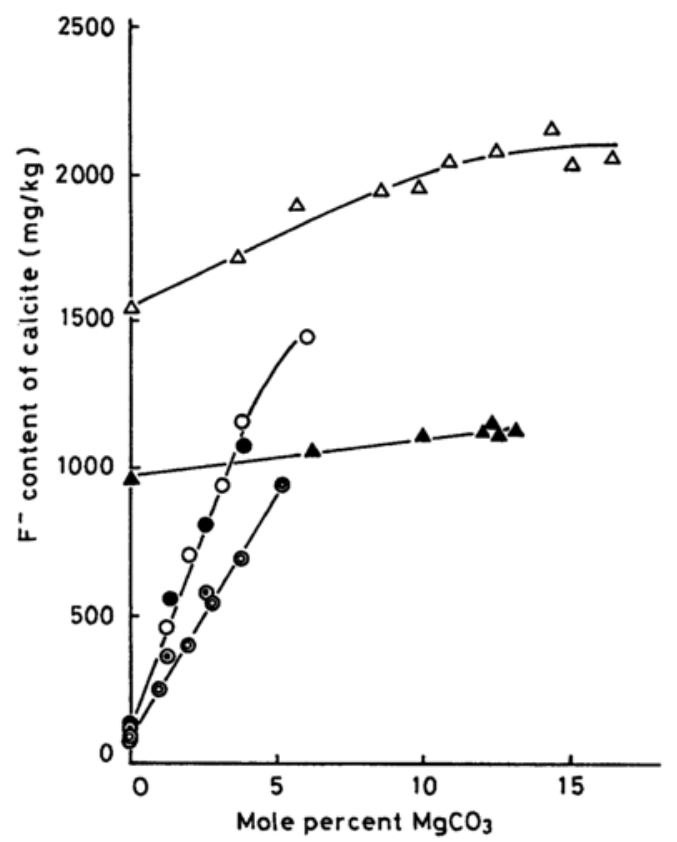

Fig. 3. Fluorine content of calcite, plotted against magnesium carbonate content of calcite. Stirring system

○ $\mathrm{F}^{-}: 2.0 \mathrm{mg} / \mathrm{l} \mid \mathrm{Ca}\left(\mathrm{HCO}_{3}\right)_{2}\left(\mathrm{Ca}^{2+}: 360 \mathrm{mg} / \mathrm{l}\right)+\mathrm{NaF}$ ๑ $\left.F^{-}: 1.0 \mathrm{mg} / \mathrm{l}\right\}\left(F^{-}: 1.0\right.$ or $\left.2.0 \mathrm{mg} / \mathrm{l}\right)+\mathrm{MgCl}_{2}\left(\mathrm{Mg}^{2+}\right.$ : Non-stirring system 0 to $0.3 \mathrm{~g} / \mathrm{l}) \longrightarrow$ Calcite

- $F^{-}: 2.0 \mathrm{mg} / \mathrm{l}$ I $\mathrm{Ca}\left(\mathrm{HCO}_{3}\right)_{2}\left(\mathrm{Ca}^{2+}: 360 \mathrm{mg} / \mathrm{l}\right)+\mathrm{NaF}$ - $\left.F^{-}: 1.0 \mathrm{mg} / \mathrm{l}\right\}\left(F^{-}: 1.0\right.$ or $\left.2.0 \mathrm{mg} / \mathrm{l}\right)+\mathrm{MgCl}_{2}\left(\mathrm{Mg}^{2+}\right.$ : 0 to 0.10 or 0 to $0.15 \mathrm{~g} / \mathrm{l}) \rightarrow$ Calcite $\triangle F^{-}: 2.0 \mathrm{mg} / \mathrm{l}, \mathrm{Ca}\left(\mathrm{HCO}_{3}\right)_{2}\left(\mathrm{Ca}^{2+}: 360 \mathrm{mg} / \mathrm{l}\right)+\mathrm{NaF}$ - $\left.F^{-}: 1.0 \mathrm{mg} / \mathrm{l}\right\}\left(F^{-}: 1.0\right.$ or $\left.2.0 \mathrm{mg} / \mathrm{l}\right)+\mathrm{MgCl}_{2}\left(\mathrm{Mg}^{2+}\right.$ : 0 to $1.27 \mathrm{~g} / \mathrm{l})+$ Na-citrate (citrate: $1.06 \mathrm{mmol} / \mathrm{l}) \longrightarrow$ Calcite

Figure 4 shows the relationship between the concentration of magnesium ions in a parent solution and the magnesium carbonate content of formed low Mg-calcite. The magnesium carbonate content of low Mg-calcite increases with increasing concentration of magnesium ions in the parent solution. Stirring of $\mathrm{Ca}\left(\mathrm{HCO}_{3}\right)_{2}+\mathrm{NaF}+\mathrm{MgCl}_{2}$ parent solution 
slightly depresses the incorporation of magnesium ions into low $\mathrm{Mg}$-calcite, as reported in the $\mathrm{Ca}\left(\mathrm{HCO}_{3}\right)_{2}+\mathrm{Na}$-citrate (or Na-malate) $+\mathrm{MgCl}_{2}$ solution system (Kitano et al., 1976). Throughout these experimental results the fluorine content of low Mg-calcite is concluded to be controlled sensitively by the magnesium carbonate content of low Mg-calcite. This experimental result is in good agreement with an observed positive relationship between fluorine and magnesium carbonate contents of marine skeletal carbonates (OHDE and KITANO, 1980).

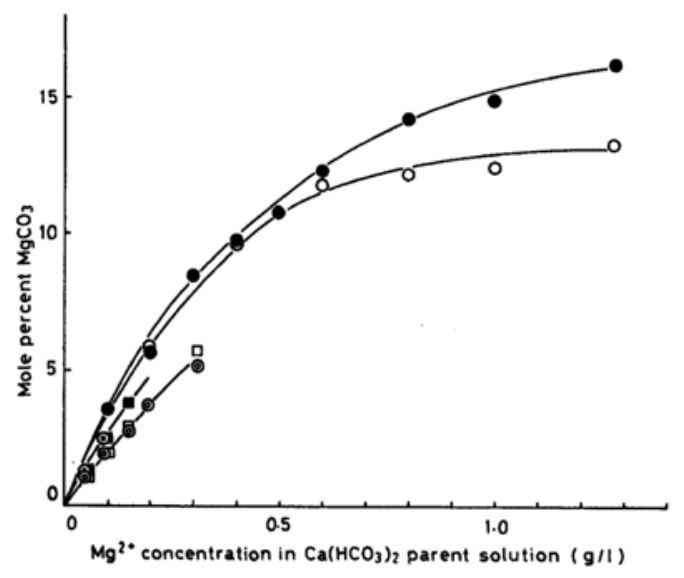

Fig. 4. Relation between the concentration of magnesium ions in a parent solution and the magnesium carbonate content of calcite.

Stirring system

ㅁ $\mathrm{F}^{-}: 2.0 \mathrm{mg} / \mathrm{l}, \mathrm{Ca}\left(\mathrm{HCO}_{3}\right)_{2}\left(\mathrm{Ca}^{2+}: 360 \mathrm{mg} / \mathrm{l}\right)+\mathrm{NaF}$

๑ $\left.\mathrm{F}^{-}: 1.0 \mathrm{mg} / \mathrm{l}\right\}\left(\mathrm{F}^{-}: 1.0\right.$ or $\left.2.0 \mathrm{mg} / \mathrm{l}\right)+\mathrm{MgCl}_{2}\left(\mathrm{Mg}^{2+}\right.$ : 0 to $0.3 \mathrm{~g} / \mathrm{l}) \longrightarrow$ Calcite

Non-stirring system

- $\left.F^{-}: 2.0 \mathrm{mg} / \mathrm{l}\right\} \mathrm{Ca}\left(\mathrm{HCO}_{3}\right)_{2}\left(\mathrm{Ca}^{2+}: 360 \mathrm{mg} / \mathrm{l}\right)+\mathrm{NaF}$ - $\left.F^{-}: 1.0 \mathrm{mg} / \mathrm{l}\right\}\left(F^{-}: 1.0\right.$ or $\left.2.0 \mathrm{mg} / \mathrm{l}\right)+\mathrm{MgCl}_{2}\left(\mathrm{Mg}^{2+}\right.$ : 0 to 0.10 or $0.15 \mathrm{~g} / \mathrm{l}) \longrightarrow$ Calcite

- $F^{-}: 2.0 \mathrm{mg} / \mathrm{l}, \mathrm{Ca}\left(\mathrm{HCO}_{3}\right)_{2}\left(\mathrm{Ca}^{2+}: 360 \mathrm{mg} / \mathrm{l}\right)+\mathrm{NaF}$ ○ $\left.F^{-}: 1.0 \mathrm{mg} / \mathrm{l}\right\}\left(F^{-}: 1.0\right.$ or $\left.2.0 \mathrm{mg} / \mathrm{l}\right)+\mathrm{MgCl}_{2}\left(\mathrm{Mg}^{2+}\right.$ : 0 to $1.27 \mathrm{~g} / \mathrm{l}$ ) + Na-citrate (citrate: $1.06 \mathrm{mmol} / \mathrm{l}) \longrightarrow$ Calcite

Kitano et al., (1980) reported that the incorporation of copper (II) or zinc ions into magnesium-free calcite causes an increase in the fluorine content, partly owing to the substitution of fluoride ions for hydroxide ions in the calcite. The effect of magnesium carbonate content of low Mg-calcite on the fluoride incorporation into low $\mathrm{Mg}$-calcite is similar to that for copper (II) or zinc ions. The physical and chemical similarity of magnesium ions to copper (II) and zinc ions suggests that the mechanism for the effect of magnesium ions on the fluoride incorporation is similar to that of copper (II) or zinc ions. Magnesium carbonate exists easily as basic magnesium carbonate having hydroxide ions in its structure. Fluoride ions in a solution can substitute easily for hydroxide ions in the mineral. The substitution of magnesium ions for calcium ions of calcite may be favorable to the substitution of fluoride ions for hydroxide ions. Thus a good linear relationship may be observed between fluorine and magnesium carbonate contents of low Mg-calcites formed from $\mathrm{Ca}\left(\mathrm{HCO}_{3}\right)_{2}+\mathrm{NaF}+\mathrm{MgCl}_{2}$ parent solutions (see Fig. 3).

Effect of citrate and magnesium ions - Influence of magnesium or citrate ions on the fluoride incorporation was examined in the calcium bicarbonate solutions containing both magnesium and citrate ions; $\mathrm{Ca}\left(\mathrm{HCO}_{3}\right)_{2}+\mathrm{NaF}\left(\mathrm{F}^{-}\right.$: 1.0 or $2.0 \mathrm{mg} / \mathrm{l}$ ) + Na-citrate (citrate: 0 to 1.58 $\mathrm{mmol} / \mathrm{l})+\mathrm{MgCl}_{2}\left(\mathrm{Mg}^{2+}: 0\right.$ to $\left.1.27 \mathrm{~g} / \mathrm{l}\right) \longrightarrow$ Calcite and/or Aragonite. The parent solutions in this experimental system were allowed to stand with occasional agitation (non-stirring system).

Magnesian calcite (a solid solution between $\mathrm{CaCO}_{3}$ and $\mathrm{MgCO}_{3}$ ), aragonite or the mixture of calcite (mostly magnesian calcite) and aragonite was precipitated from the parent solutions containing $1.27 \mathrm{~g} / 1$ of magnesium ions and 0 to $1.58 \mathrm{mmol} / 1$ of citrate ions. The proportion of magnesian calcite to aragonite depended on the concentration of citrate ions in the parent solution: Pure aragonite is formed from the parent solutions containing both 0 to $0.26 \mathrm{mmol} / 1$ of citrate ions and $1.27 \mathrm{~g} / 1$ of magnesium ions, the mixture of magnesian calcite and aragonite from those containing both $0.53 \mathrm{mmol} / 1$ of citrate ions and 1.27 $\mathrm{g} / 1$ of magnesium ions, and magnesian calcite alone from those containing both more than $0.79 \mathrm{mmol} / 1$ of citrate ions and $1.27 \mathrm{~g} / 1$ of 
magnesium ions.

As Fig. 1 shows, the amount of fluoride ions incorporated into aragonite is almost constant, about $1,000 \mathrm{mg} / \mathrm{kg}$. The fluorine content of magnesian calcite (magnesium carbonate content, 11.2 to $14.4 \%$ ) is high and slightly increases with increasing concentration of citrate ions $(0.79$ to $1.59 \mathrm{mmol} / \mathrm{l})$ in the parent solution, where the magnesian calcites precipitated from the parent solutions containing 0.79 , 1.05 and $1.59 \mathrm{mmol} / \mathrm{l}$ of citrate ions with $1.27 \mathrm{~g} / 1$ of magnesium ions contain $11.2,12.2$ and $14.4 \mathrm{~mol}$ percent of magnesium carbonate, respectively.

Magnesium-free calcite or magnesian calcite was precipitated from the parent solutions containing 0 to $1.27 \mathrm{~g} / 1$ of magnesium ions and $1.05 \mathrm{mmol} / 1$ of citrate ions. Figures 2 and 3 show the following: (a) The amounts of fluoride ions incorporated into magnesium-free calcite and also magnesian calcite formed from the parent solution containing $1.05 \mathrm{mmol} / 1$ of citrate ions are larger than those without citrate ions. It is noted that the presence of citrate ions in a parent solution especially increases the fluorine content of magnesium-free calcite, as shown earlier in Fig. 1. (b) The amount of fluoride ions incorporated into magnesian calcite is high, but tends to increase slightly with increasing magnesium concentration in the parent solution and with increasing magnesium carbonate content of the magnesian calcite, in contrast to a remarkable increase in the fluorine content of low $\mathrm{Mg}$ calcite formed in the parent solution without sitrate ions. These experimental results are interesting, but the mechanism remains unsolved.

Fluorine content of calcareous skeletons in marine organisms - The results of the present study suggest that certain organic materials in body fluids of marine calcareous organisms increase the fluorine content of their skeletons.

Fluorine content of calcitic foraminiferal tests, which contain lower than $0.5 \%$ of magnesium carbonate, is within 300 and $400 \mathrm{mg} / \mathrm{kg}$ (OKumura, 1980). This content is higher than
60 to $200 \mathrm{mg} / \mathrm{kg}$ of fluorine content of low $\mathrm{Mg}$ calcite (lower than $0.5 \%$ of magnesium carbonate) precipitated inorganically from a parent solution containing $1.0 \mathrm{mg} / 1$ of fluoride ions and no organic anions, as seen from Fig. 3. Such a higher fluorine content of foraminiferal tests may be partly due to the effect of certain organic materials in their body fluids. However, the extent of this effect can not be estimated quantitatively, because of a lack of the exact information on organic materials in their body fluids. The relationship between organic materials of body fluids and fluorine content of skeletal parts in calcareous marine organisms should be further investigated.

Marine carbonate sediments, which consist mostly of foraminiferal tests, remove $11 \%$ of fluorine supplied into the oceans through rivers, as already reported by the present authors (1983).

The present paper shows the experimental results about the influence of certain organic materials in the parent solution on the fluoride incorporation into low $\mathrm{Mg}$-calcite, high $\mathrm{Mg}$ calcite and aragonite. These experimental results seem to be useful for understanding the fluoride incorporation into marine calcareous skeletons.

Acknowledgement-This work was supported by the grants from the Ministry of Education in Japan and also from the Nippon Life Insurance Foundation.

\section{REFERENCES}

AKaiWA, H. and Aizawa, S. (1979) Fluorine contents of Permian carbonate rock in central Japan. Chem. Geol. 27, 157-169.

CARPENTER, R. (1969) Factors controlling the marine geochemistry of fluorine. Geochim. Cosmochim. Acta 33, 1153-1167.

CARTER, P. W. (1978) Adsorption of amino acidcontaining organic matter by calcite and quartz. Geochim. Cosmochim. Acta 42, 1239-1242.

CARTER, P. W. and MitTerer, R. M. (1978) Amino acid composition of organic matter associated with carbonate and non-carbonate sediments. Geochim. Cosmochim. Acta 42, 1231-1238.

GREENHALGH, R. and Riley, J. P. (1961) The determination of fluorides in natural waters, with particular 
reference to sea water. Anal. Chim. Acta 25, 179188.

ICHIKUNI, M. (1979) Uptake of fluoride by aragonite. Chem. Geol. 27, 207-214.

Kitano, Y. and Hood, W. H. (1965) The influence of organic material on the polymorphic crystallization of calcium carbonate. Geochim. Cosmochim. Acta 29, 29-41.

Kitano, Y. and KanamoRi, N. (1966) Synthesis of magnesian calcite at low temperatures and pressures. Geochem. J. 1, 1-10.

Kitano, Y., TOKUYAma, A. and KANAMORI, N. (1968) Measurement of the distribution coefficient of zinc and copper between carbonate precipitate and solution. J. Earth Sci. Nagoya Univ. 16, 1-102.

Kitano, Y., Kanamori, N. and OOMRI, T. (1971) Measurements of distribution coefficients of strontium and barium between carbonate and solution Abnormally high values of distribution coefficients measured at early stages of carbonate formation. Geochem. J. 4, 183-206.

Kitano, Y., YoshioKa, S. and Kanamori, N. (1972) The mineral composition of calcium carbonate formed in the processes of separation from bicarbonate solution Kaseki 23/24, 3-14 (in Japanese).

Kitano, Y. and OKUMURA, M. (1973) Coprecipitation of fluoride with calcium carbonate. Geochem. J. 7, 37-49.

Kitano, Y., Kanamori, N. and Yoshioka, S. (1976) Influence of chemical species on the crystal type of calcium carbonate. in The Mechanisms of mineralization in the invertebrates and plants. (eds. N. WATABE and K. M. WILBUR), University of South Carolina Press, 191-202.

Kitano, Y., OKumura, M. and IdogaKi, M. (1980) Abnormal behaviors of copper (II) and zinc ions in parent solution at the early stage of calcite formation. Geochem. J. 14, 167-175.

LahanN, R. W. and Campbell, R. C. (1980) Adsorption of palmitic acid on calcite. Geochim. Cosmochim. Acta 44, 629-634.

OHDE, S. and KITANO, Y. (1980) Incorporation of fluoride into $\mathrm{Ca}-\mathrm{Mg}$ carbonates. Geochem. J. 14, 321-324.

OKUMURA, M. (1980) The geochemical behaviors of inorganic anions at the formation of calcium carbonate. Ph.D. Thesis, Nagoya University, pp. 168 (in Japanese).

OKumura, M., Kitano, Y. and Idogaki, M. (1983) Removal of anions by carbonate sedimentation from seawater. Geochem. J. 17, 105-110. 